\title{
Changes in Nuclear Protein Contents of Root Cells during Germination
}

\author{
J. E. Thomas and D. Davidson \\ Department of Biology, McMaster University, \\ Hamilton, Ontario, Canada L8S 4K1
}

Accepted August 12, 1983

Changes in the protein composition of nuclei occur in many cell types as they undergo transitions from one state to another. Total histone content of nuclei shows only a 2-fold range of values over a cell cycle (Prescott 1966, Borun 1975) but they undergo modifications in the degree of acetylation or phosphorylation that have been related to chromatin activation (Chahal, Matthews and Bradbury 1980) or chromosome condensation (Bradbury, Inglis, Matthews and Langan 1974, Matsumoto, Yasuda, Mita, Marunouchi and Yamada 1980). The onset of differentiation may be accompanied by a decrease in total nuclear protein content (Mirsky and Ris 1949, Le Stourgeon, Rusch, Totten and Forer 1974). Transition from the $\mathrm{G}_{0}$ state to the proliferative state includes increases in the number of different types of proteins (Stein and Baserga 1970, Le Stourgeon and Rusch 1971, Levy, Levy, Rosenberg and Simpson 1973, Jeter and Cameron 1974) and in the total acidic protein content of nuclei (Mirsky and Ris 1949, Le Stourgeon et al, 1974). This latter type of transition parallels the change in meristem cells of roots of germinating seeds: cells of the dormant seed become activated and enter a proliferative phase as the seed germinates.

In the radicle of the dry seed of Vicia faba about $90 \%$ of the cells have a $\mathrm{G}_{1}$ DNA content (Jakob and Bovey 1969). When seeds imbibe water, cells become activated; the first cells to complete a cell cycle enter mitosis in a semi-synchronous wave (Davidson 1966, Murin 1967). In the subsequent 2-3 cycles: 1) the root meristem achieves a steady-state condition; as it does so, mean cell area decreases but mean nuclear area remains fairly constant (Thomas and Davidson 1981, 1982, 1983). Since, in other systems, an increase in nuclear protein content is associated with a shift from the $\mathrm{G}_{0}$ to the proliferative condition, we have measured nuclear protein contents during the first 144 hours of germination in order to determine: 1) whether mean protein content of nuclei changes as root meristem cells progress from the dormant condition into a proliferative stage in spite of the constancy of mean nuclear area; 2) what is the relationship between mean area and mean protein content?

Mean protein content of nuclei, as we report here, decreased as cells became proliferatively active, suggesting that the relationship between protein and size of nuclei is somewhat flexible. In order to explore this possibility we treated roots with 5-aminouracil: this extends the duration of $\mathrm{G}_{2}$ (Socher and Davidson 1971) and the cells and nuclei delayed in their progress through interphase show significant increases in size (Davidson, Golding and Armstrong 1978). Mean nuclear pro- 
tein contents were determined. Though some increase in protein content was found, it did not equal the nuclear size increase in magnitude. This supports the conclusion that, during the first few days of germination, the relationship between size and protein content of nuclei is not fixed. These results agree with those from other systems that variation in dry mass (Lyndon 1967) and protein content (Armstrong and Davidson 1982) is to some extent independent in variation of size of nuclei.

\section{Materials and methods}

Beans, Vicia faba L. cv. Sutton's Prolific Longpod, were notched above the embryo axis, placed on their sides between two layers of cheese cloth and distilled water was added to a depth of 5-10 mm. After 24 hours the seed coats were removed, the beans rinsed in distilled water and growing roots were obtained in the following ways: i. seeds were skewered with stainless steel rods and placed, with the root down, in aerated distilled water, which was changed every 24 hours. They were fixed, at intervals, upto 144 hours from the start of imbibition; ii. seeds were planted in moistened sand $(25 \mathrm{ml}$ of water $/ 100 \mathrm{ml}$ of sand). After 96 hours from the beginning of imbibition, seedlings were removed from the sand, rinsed, skewered with steel rods and grown in tanks of aerated distilled water.

For 5-aminouracil (5-AU) treatments, some seedlings grown in moistened sand and then transferred to tanks of water, as described above, were placed in tanks containing a $4 \mathrm{mM}$ solution of 5-AU. They were treated for 6-24 hours. Seeds were imbibed and all seedlings were grown at $20^{\circ} \mathrm{C}$.

Protein Determinations. Nuclei were extracted from the 1-2 $\mathrm{mm}$ of the apex of the root meristem using a method modified from Van't Hof (1975). At each time 5 root tips were placed in ice-cold $4 \%$ formaldehyde $(\mathrm{v} / \mathrm{v})$ in $0.132 \mathrm{M}$ phosphate buffer (pH 6.8). After $5 \mathrm{~min}$ they were transferred to ice-cold $0.132 \mathrm{M}$ phosphate buffer. In order to isolate nuclei, each meristem was placed in 2 drops of fixative on an ice-cold alcohol cleaned slide and macerated. This released the nuclei from the cells. Large pieces of cellular debris were removed and the slides were partially flooded with fixative. Nuclei were spread around the slide in order to minimize cytoplasmic background and then left to air dry.

Proteins were stained using a modification of the method of Mitchell (1967). In order to make comparisons between different samples valid, all slides were stained at the same time. Slides were placed in 1:1 mixture $(\mathrm{v} / \mathrm{v})$ of acetone: ethanol for $30 \mathrm{~min}$ and then in $0.15 \mathrm{ml} \mathrm{2:4}$ dinitro-1-fluorobenzene (DNFB) in $100 \mathrm{ml}$ ethanol plus $1 \mathrm{ml} 1 \mathrm{M}$ sodium bicarbonate and $5 \mathrm{ml}$ distilled water. Nuclei were stained for 12 hours at $65^{\circ} \mathrm{C}$. After staining, slides were washed in $70 \%$ ethanol (15 min), warm distilled water $\left(30^{\circ} \mathrm{C}, 15 \mathrm{~min}\right)$ and then dehydrated in $70 \%$ ethanol $(5 \mathrm{~min})$, $95 \%$ ethanol (10 min), $100 \%$ ethanol ( 2 changes for $10 \mathrm{~min}$ each) and xylene $(5 \mathrm{~min})$. Nuclei were mounted in Permount.

Measurements of total nuclear protein were made using the 2 wavelength method of Patau (1952). The wavelengths used were 415 and $445 \mathrm{~nm}$; i.e. the peak and $50 \%$ of the peak absorption for the DNFB-protein complex. All measure- 
ments were made, at a magnification of $630 \times$, using a Leitz microspectrophotometer $(\mathrm{NA}=0.85)$. At each fixation time, 20 to 144 hours from the beginning of imbibition, 100 interphase nuclei, 20 from each of 5 meristems, were measured. Length and width of each nucleus were measured with an ocular micrometer in order to calculate nuclear area.

\section{Results}

Protein content of nuclei was determined 20 to 144 hours from the onset of germination. Mean nuclear protein contents were similar, in roots of the same age from the onset of germination, whether they had been grown in water or in moistened sand; e.g. $68 \pm 23$ and $66 \pm 20$ A.U. at 50 hours (Tables 1 and 2). The pattern of change in mean protein contents was also similar in the two groups of roots; it increased upto 50 hours, as seeds moved through $S$ and into $G_{2}$ of the first cell cycle, and subsequently decreased. In roots grown in water, mean nuclear protein con-

Table 1. Mean \pm S.D. and range in area and in protein contents of nuclei of primary roots of Vicia faba. Each value is based on 100 nuclei. Seeds were imbibed for 24 hours and then grown in tanks of aerated distilled water for upto 144 hours

\begin{tabular}{cccccc}
\hline \hline \multirow{2}{*}{$\begin{array}{c}\text { Hours } \\
\text { after addition } \\
\text { of water }\end{array}$} & \multicolumn{2}{c}{ Nuclear area $\left(\mu \mathrm{m}^{2}\right)$} & & \multicolumn{2}{c}{ Nuclear protein (A.U.) } \\
\cline { 3 - 3 } \cline { 5 - 6 } & mean \pm S.D. & range & & mean \pm S.D. & range \\
\hline 20 & $97 \pm 28$ & $60-172$ & & $55 \pm 18$ & $32-112$ \\
36 & $97 \pm 27$ & $52-156$ & & $62 \pm 25$ & $34-150$ \\
50 & $101 \pm 24$ & $62-177$ & & $68 \pm 23$ & $30-158$ \\
68 & $102 \pm 24$ & $62-169$ & & $50 \pm 17$ & $19-89$ \\
96 & $96 \pm 18$ & $62-145$ & & $43 \pm 14$ & $19-86$ \\
144 & $89 \pm 21$ & $52-171$ & & $38 \pm 11$ & $18-61$ \\
\hline
\end{tabular}

tent fell by $44 \%$ between 50 and 144 hours (Table 1) and by $33 \%$, between 50 and 96 hours, in roots grown in moistened sand (Table 2). In both sets of roots the decreases are significant $(\mathrm{P}=0.05)$; i.e. $68 \pm 23$ to $38 \pm 11$ A.U. and $66 \pm 20$ to $44 \pm 13$ A.U. (Tables 1 and 2). The modal value of nuclear protein content also increased upto 50 hours and then decreased (Fig. 1).

The range of values of nuclear protein contents showed a similar pattern of change. It increased upto 50 hours and subsequently decreased. We conclude that nuclear protein contents decrease when root meristematic cells of germinating beans become active in proliferation. This decrease in mean values and in the range of values occurred without a decrease of similar magnitude in nuclear size: i.e. a $44 \%$ decrease in mean protein contents between 50 and 144 hours was accompanied by only an $11.8 \%$ decrease in mean nuclear area (Table 1 ). Thus the average concentration of total protein, per unit volume of nucleus, decreases significantly as cells of the root meristem achieve an asynchronous, steady-state condition. This decrease has been analysed in greater detail by selecting nuclei of specific sizes and comparing their protein contents. 


\section{Protein Contents of Nuclei of Selected Area Classes}

In order to determine whether the pattern of changes in mean nuclear protein content occurred in nuclei of specific area classes we selected nuclei of areas 71,82 ,

Table 2. Mean \pm S.D. area and mean \pm S.D. and range of protein contents of nuclei. Seeds were imbibed in $5 \mathrm{~mm}$ of water for 24 hours, grown in moistened sand $(25 \mathrm{ml}$ water $/ 100 \mathrm{ml}$ sand) from 24 to 96 hours and then transferred to tanks of water. Some seedlings were transferred, after 24 hours in water, to a $4 \mathrm{mM}$ solution of 5-AU for 6,14 or 24 hours.

Each value is based on 100 nuclei

\begin{tabular}{cccccccc}
\hline \hline \multicolumn{3}{c}{ Hours in } & & & Nuclear area $\left(\mu \mathrm{m}^{2}\right)$ & & \multicolumn{2}{c}{ Nuclear protein content (A.U.) } \\
\cline { 1 - 3 } \cline { 6 - 7 } \cline { 6 - 7 } sand & water & $5-\mathrm{AU}$ & & mean \pm S.D. & & mean \pm S.D. & range \\
\hline 36 & - & - & & $94 \pm 26$ & & $60 \pm 21$ & $33-113$ \\
50 & - & - & & $104 \pm 22$ & & $66 \pm 20$ & $24-116$ \\
68 & - & - & & $96 \pm 17$ & & $46 \pm 13$ & $19-77$ \\
96 & - & - & & $93 \pm 21$ & & $44 \pm 13$ & $15-76$ \\
96 & 30 & - & & $89 \pm 19$ & & $42 \pm 16$ & $20-89$ \\
96 & 48 & - & & $93 \pm 29$ & & $41 \pm 15$ & $16-84$ \\
96 & 24 & 6 & & $98 \pm 24$ & & $38 \pm 14$ & $19-87$ \\
96 & 24 & 14 & & $101 \pm 30$ & & $47 \pm 15$ & $17-84$ \\
96 & 24 & 24 & & $106 \pm 28$ & & $43 \pm 15$ & $12-87$ \\
\hline
\end{tabular}

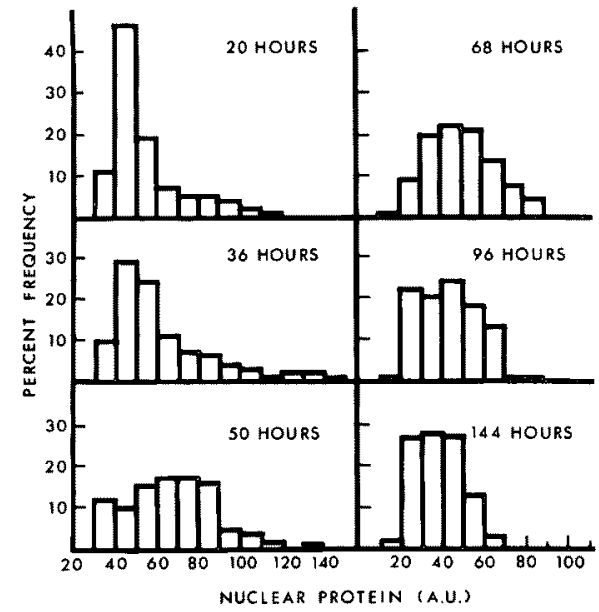

Fig. 1. Percent frequency histograms of nuclear protein contents in root meristems of Vicia faba. Seeds were imbibed in $5-10 \mathrm{~mm}$ of water for 24 hours and then grown in tanks of water. The hours given are timed from the start of imbibition. At each time, 100 nuclei were isolated from 5 root meristems. Protein values are given in arbitrary units (A.U.).
93 and $100 \mu \mathrm{m}^{2}$. They were taken from those nuclei used for Table 1 and they were chosen because they yielded, in most cases, samples of 12-20 nuclei for each area chosen. These selected nuclei, chosen solely on the basis of their area, demonstrate that the conclusions presented earlier for changes in mean protein content of an overall sample of 100 nuclei, are borne out by nuclei of specific area classes. That is, for each area class mean protein content increases upto 50 hours and decreases from 50 to 144 hours (Table 3 ). The additional conclusion to be drawn is that small nuclei at $20-50$ hours have a higher mean protein content than larger nuclei at 144 hours; cf. the 71 $\mu \mathrm{m}^{2}$ class at 20 hours, with a mean protein content of $44.9 \pm 9.8$ A.U., with the $110 \mu \mathrm{m}^{2}$ area class at 144 hours, with a mean protein content of $41.7 \pm$ 10.4 A.U.

Nuclear protein contents cover a 2- to 3-fold range of values for a specific nuclear size class (Table 3 ). The extent of the overlap in protein content of nuclei 
of identical areas is demonstrated by comparing probit plots of protein content of three samples of nuclei. Nuclei of areas 60,82 and $100 \mu \mathrm{m}^{2}$ were selected from the total sample scored (Table 4); they were chosen because their sample sizes were large, 83, 251 and 181 nuclei respectively, and because the $60-100 \mu \mathrm{m}^{2}$ spread covers almost a 2-fold increase in nuclear area. The probit plots (Fig. 2) reveal the considerable overlap in protein contents of nuclei of different areas: $\sim 65 \%$ of the $100 \mu \mathrm{m}^{2}$ area nuclei had protein values that fell in the range covered by the $60 \mu \mathrm{m}^{2}$ area nuclei, i.e. 18-65 A.U. (Fig. 2).

Table 3. Mean \pm S.D. and range of proteins in nuclei of selected area classes. Number of nuclei in each area class is given. Data taken from the nuclei reported in Table 1

\begin{tabular}{|c|c|c|c|c|}
\hline \multirow{2}{*}{$\begin{array}{l}\text { Hours from } \\
\text { addition } \\
\text { of water }\end{array}$} & \multirow{2}{*}{$\begin{array}{l}\text { Nuclear } \\
\text { area } \\
\left(\mu \mathrm{m}^{2}\right)\end{array}$} & \multirow{2}{*}{$\begin{array}{c}\text { Number } \\
\text { of } \\
\text { nuclei }\end{array}$} & \multicolumn{2}{|c|}{ Nuclear protein (A.U.) } \\
\hline & & & mean \pm S.D. & range \\
\hline \multirow{4}{*}{20} & 71 & 17 & $44.9 \pm 9.8$ & $31.5-69.4$ \\
\hline & 82 & 16 & $50.0 \pm 7.7$ & $38.4-66.2$ \\
\hline & 93 & 12 & $50.4 \pm 13.7$ & $40.8-91.1$ \\
\hline & 110 & 12 & $65.1 \pm 25.6$ & $34.0-112.3$ \\
\hline \multirow{4}{*}{36} & 71 & 16 & $52.4 \pm 13.6$ & $33.6-82.2$ \\
\hline & 82 & 21 & $52.4 \pm 10.9$ & $37.4-78.4$ \\
\hline & 93 & 13 & $56.9 \pm 14.2$ & $37.4-80.8$ \\
\hline & 110 & 13 & $72.0 \pm 21.0$ & $49.1-114.2$ \\
\hline \multirow{4}{*}{50} & 71 & 16 & $48.4 \pm 15.0$ & $30.0-82.3$ \\
\hline & 82 & 15 & $64.4 \pm 14.0$ & $43.5-89.0$ \\
\hline & 93 & 19 & $70.0 \pm 12.7$ & $43.2-92.3$ \\
\hline & 110 & 19 & $76.6 \pm 21.5$ & $30.6-115.9$ \\
\hline \multirow{4}{*}{68} & 71 & 7 & $35.5 \pm 10.3$ & $22.0-49.1$ \\
\hline & 82 & 27 & $47.6 \pm 13.4$ & $22.0-69.0$ \\
\hline & 93 & 13 & $54.7 \pm 14.5$ & $39.4-78.2$ \\
\hline & 110 & 15 & $51.8 \pm 16.0$ & $24.9-86.1$ \\
\hline \multirow{4}{*}{96} & 71 & 12 & $29.6 \pm 5.6$ & $23.3-41.2$ \\
\hline & 82 & 25 & $36.8 \pm 11.4$ & $18.7-63.5$ \\
\hline & 93 & 18 & $50.0 \pm 12.6$ & $23.7-72.2$ \\
\hline & 110 & 20 & $52.0 \pm 10.5$ & $22.0-68.0$ \\
\hline \multirow{4}{*}{144} & 71 & 24 & $33.5 \pm 9.2$ & $22.1-54.8$ \\
\hline & 82 & 29 & $38.5 \pm 9.3$ & $24.4-58.9$ \\
\hline & 93 & 16 & $43.3 \pm 7.6$ & $28.7-60.7$ \\
\hline & 110 & 8 & $41.7 \pm 10.4$ & $27.9-54.0$ \\
\hline
\end{tabular}

The probit plots also revealed that protein contents of nuclei were not normally distributed (Fig. 2) since none of the three distributions appeared to fit a single straight line. From the range in protein contents of nuclei (Table 3; Fig. 2) it appears that, for individual nuclei, area may vary, to a large extent, independently of the amount of protein present. When mean protein content is plotted against mean nuclear area, however, a clear relationship between these two parameters emerges.

Nuclei were grouped into size classes (Table 4). Some classes contained few nuclei, i.e. 1-11, and their mean protein contents showed little correlation between 
nuclear area and protein content. Therefore we plotted mean protein content against nuclear area for samples of 40 or more nuclei and we added, at the two extremes of the range of nuclear areas a sample of 20 nuclei, the $49 \mu \mathrm{m}^{2}$ class, and one

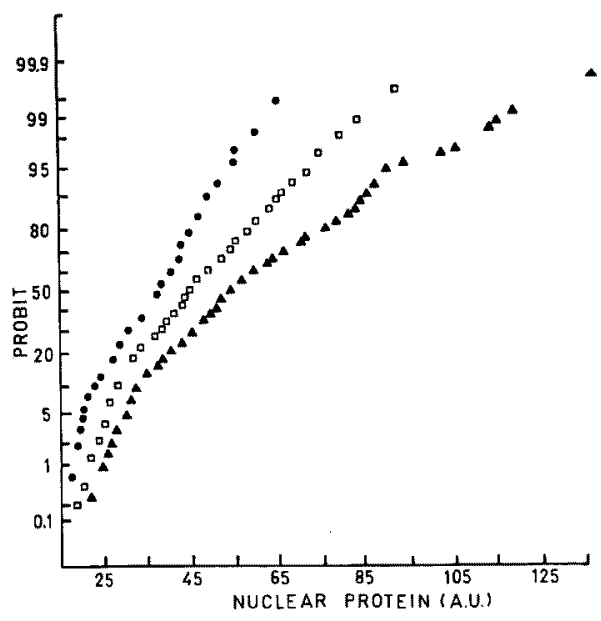

Fig. 2. Percent cumulative frequency plot (Probit) of protein contents of nuclei of area $60 \mu \mathrm{m}^{2}(\bullet), 82 \mu \mathrm{m}^{2}$ $(\square)$ and $110 \mu \mathrm{m}^{2}(\Delta)$. The three samples consisted of 83, 251 and 181 nuclei, respectively. Protein values are given in arbitrary units.

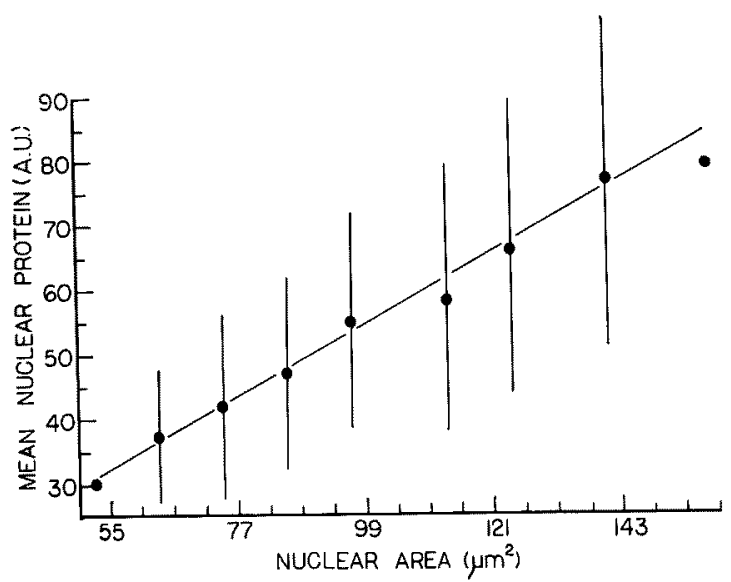

Fig. 3. Mean nuclear protein content plotted against nuclear area. Nuclear areas were grouped in $5.5 \mu \mathrm{m}^{2}$ intervals. Each mean nuclear protein content is based on a sample of 40 or more nuclei, except the values of $49 \mu \mathrm{m}^{2}$ and $154 \mu \mathrm{m}^{2}$, which are based on 20 and 17 nuclei. Protein contents are given in arbitrary units (A.U.). of 17 nuclei, the $154 \mu \mathrm{m}^{2}$ class (Table 4). The plot (Fig. 3) reveals a clear linear relationship between the two parameters. The line has a slope of 0.474 and a y-intercept of 6.45 A.U. Thus, when fairly large samples of nuclei are scored their mean protein content increases in a regular fashion as their mean area increases. The correlation coefficient for the samples plotted in Fig. 3 was calculated: $r=0.993$. By extrapolation it can be seen that protein content of a nucleus increased-1.8 to 1.9-fold for one doubling in nuclear area.

Response to Treatment with 5-AU

Seedlings grown in sand from 24 to 96 hours were transferred to tanks of water and after 24 hours they were treated with 5-AU for 6,14 or 24 hours. Treatment with 5-AU produced a $14 \%$ increase in mean nuclear area: from $93 \pm 29 \mu \mathrm{m}^{2}$ in roots grown in water for 48 hours to $106 \pm 28 \mu \mathrm{m}^{2}$ in roots treated with 5-AU for 24 hours (Table 2). But there was only a minimal increase in mean protein content, i.e. $41 \pm 15$ A.U. to $43 \pm 15$ A.U. (Table 2). The range of nuclear protein contents also changed very little over the 24 hour treatment with 5-AU (Table 2). Although treatment with 5-AU brings mean nuclear area back to the value seen at 50 hours, i.e. $106 \pm 28 \mu \mathrm{m}^{2}$, cf. $104 \pm 22 \mu \mathrm{m}^{2}$, mean protein content did not return to the initial high value: it was only $43 \pm 15$ A.U. at $96+24+24$ hours, cf. $68 \pm 20$ A.U. at 50 hours 
(Table 2). This is further evidence that, at different stages of growth, mean protein content may vary independently of mean nuclear area.

\section{Discussion}

The first wave of semi-synchronous mitosis appears in root meristems of germinating $V . f a b a$ at about 50 hours (Thomas and Davidson 1981). From the

Table 4. Mean \pm S.D. and range of protein contents in root nuclei.

Seedlings were grown in water or in moistened sand $(25 \mathrm{ml}$ of water $/ 100 \mathrm{ml}$ sand) for up to 144 hours from the onset of imbibition. The 1202 nuclei scored were divided into area size classes; the class interval was $5.5 \mu \mathrm{m}^{2}$

\begin{tabular}{|c|c|c|c|}
\hline \multirow{2}{*}{$\begin{array}{c}\text { Nuclear area } \\
\left(\mu \mathrm{m}^{2}\right)\end{array}$} & \multirow{2}{*}{$\begin{array}{l}\text { Number of } \\
\text { nuclei }\end{array}$} & \multicolumn{2}{|c|}{ Nuclear protein (A.U.) } \\
\hline & & mean S.D. & range \\
\hline 49 & 20 & $30 \pm 9$ & $15-48$ \\
\hline 55 & 1 & 34 & \\
\hline 60 & 83 & $37 \pm 10$ & $18-65$ \\
\hline 66 & 2 & $43 \pm 11$ & $36-51$ \\
\hline 71 & 171 & $42 \pm 14$ & $22-82$ \\
\hline 77 & 21 & $37 \pm 11$ & $19-54$ \\
\hline 82 & 251 & $47 \pm 15$ & $19-98$ \\
\hline 88 & 25 & $41 \pm 12$ & $22-71$ \\
\hline 93 & 196 & $55 \pm 17$ & $22-110$ \\
\hline 99 & 24 & $45 \pm 9$ & $26-59$ \\
\hline 104 & 27 & $51 \pm 16$ & $31-92$ \\
\hline 110 & 181 & $58 \pm 21$ & $22-136$ \\
\hline 115 & 8 & $44 \pm 13$ & $45-55$ \\
\hline 121 & 90 & $66 \pm 23$ & $23-132$ \\
\hline 126 & 11 & $50 \pm 16$ & $24-84$ \\
\hline 132 & 5 & $60 \pm 13$ & $42-77$ \\
\hline 137 & 43 & $77 \pm 26$ & $39-150$ \\
\hline 143 & 4 & $57 \pm 20$ & $40-80$ \\
\hline 148 & 9 & $71 \pm 28$ & $42-128$ \\
\hline 154 & 17 & $79 \pm 25$ & $45-130$ \\
\hline 165 & 3 & $53 \pm 16$ & $36-68$ \\
\hline 170 & 7 & $85 \pm 38$ & $48-158$ \\
\hline 176 & 2 & $68 \pm 22$ & $53-84$ \\
\hline 181 & 1 & 40 & \\
\hline
\end{tabular}

onset of imbibition to 50 hours, mean cell and nuclear size increase (Thomas and Davidson 1983) and mean nuclear protein content increases (Tables 1 and 2). These changes parallel those seen in animal cells in the transition from $\mathrm{G}_{0}$ to a state of active cell growth (Le Stourgeon et al. 1974).

Once cells have completed their first mitosis and begin progress through the second and subsequent cell cycles, mean protein content of nuclei decreased. Though the decrease was progressive from 50 to 144 hours (Table 1) it appears to occur in two stages. Between 50 and 96 hours root meristems undergo a number of changes: 1) 
mean cell cycle duration decreases, to $\sim 20$ hours (Thomas and Davidson 1982); 2) mean cell area decreases (Thomas and Davidson, 1983); 3) mean nuclear protein content decreases (Tables 1 and 2). But from 96 to 144 hours mean area and mean protein content of nuclei show only slight changes (Tables 1 and 2). In this period, root meristems gradually take on the characteristics of a steady state system and the growth pattern of their cells is similar to that of other cells (Prescott 1955, Zetterberg and Killander 1965).

The analysis of the changes in cell, nuclear and protein parameters during the germination of $V$. faba suggests that the rates of i) cell growth and ii) progress through interphase are not closely coordinated. The result is that cell cycle duration is not long enough to allow cells to double their size or their nuclear protein contents, though they do double their nuclear area. This means that nuclei are competent to complete a replication and division cycle in spite of reduction in their protein content. Though some nuclear proteins must be essential for maintaining chromatin structure and gene activity, others can be lost, or reduced in amount, without affecting the ability of the nucleus to replicate and divide.

Protein content of nuclei also decreases after treatment with caffeine and, as with the results reported here, affected cells remain able to complete a cell cycle and divide (Armstrong and Davidson 1982). The difference between the two systems in which a reduction in mean nuclear protein content occurs in significant. Here we describe the reduction that occurs between 50 and 96 hours of germination: the proteins lost could either be ones required to maintain the quiescent condition of nuclei while the seeds were dormant or ones that must be lost in order to allow nuclei to undergo the reprogramming necessary for them to give rise to a steadystate population of proliferating cells. Similar proposals of programming for cell cycle changes have been made for bacteria (Kubitschek 1966) and animal cells (Liskay, Leonard and Prescott, 1979). With caffeine treated roots, however, the drop in protein content took place in nuclei of cells that were already in a steadystate condition. Even in these nuclei, therefore, a proportion of their protein molecules may be lost without reducing their ability to replicate or divide (Armstrong and Davidson 1982). The fraction of nuclear proteins that appears to be dispensible may be similar to those identified in A. proteus as nonstructural proteins that move freely between cytoplasm and nucleus (Goldstein and Ko 1981). The distribution of such proteins between nucleus and cytoplasm may be determined by physiological state of a cell, or by treatment, e.g. with caffeine or 5-AU. Changes in the relative amounts of such proteins in nuclei at different stages of root growth or in different cell lineages within a meristem may help to explain both the variation 1) in protein content of nuclei of a specific size class (Table 4) and 2) in nuclear dry mass at a specific stage of interphase (Lyndon 1967). The question that remains, however, concerns the mechanism that enables nuclei to vary so markedly in size and in protein content.

\section{Summary}

Total protein content and area of nuclei were determined for cells of the primary 
root of Vicia faba during the first 144 hours following the onset of imbibition. We wished to determine what change, if any, occurs in protein contents of nuclei as meristematic cells move from a dormant into a proliferative condition. Nuclear proteins were stained with dinitrofluorobenzene and protein content, in arbitrary units, was determined by microspectrophotometry. In the first 50 hours mean protein content of nuclei increase; this, as we have shown, is the period in which cells and nuclei increase in size as they complete their first cell cycle. During subsequent cell cycles, cell area decreases markedly, nuclear area decreases to a lesser extent; accompanying these decreases, the mean and the range of protein contents of nuclei decreased significantly. Thus, as the proliferating population of cells of a root meristem becomes steady-state, there is an absolute decrease in the concentration of total proteins within the nucleus. This was revealed particularly clearly by comparing unclei of identical areas from roots of different ages. Increases in nuclear size were induced by treatment with 5-aminouracil for upto 24 hours: this did not result in a significant increase in protein content of nuclei. These results agree with those from untreated roots that area and protein content of nuclei can, to a considerable extent, vary independently of one another.

\section{Acknowledgements}

We are grateful to the National Science and Engineering Research Council of Canada for Support (A-5050). J.E.T. was the holder of an Ontario Graduate Scholarship.

\section{References}

Armstrong, S. W. and Davidson, D. 1982. Differences in protein content of sister nuclei: evidence from binucleate and mononucleate cells. Can. J. Biochem. 60: 371-378.

Borun, T. W. 1975. Histones, differentiation and the cell cycle. In: Cell Cycle and Cell Differentiation. (ed. J. Reinert and H. Holtzer) pp. 249-290. Springer-Verlag. New York.

Bradbury, E. M., Inglis, R. J., Matthews, H. R. and Langan, T. A. 1974. Molecular basis of control of mitotic cell division in eukaryotes. Nature 249: 553-556.

Chahal, S. S., Matthews, H. R. and Bradbury, E. M. 1980. Acetylation of histone $\mathbf{H}_{4}$ and its role in chromatin structure and function. Nature 287: 76-79.

Davidson, D. 1966. The onset of mitosis and DNA synthesis in roots of germinating beans. Amer. J. Bot. 53: 491-495.

-, Golding, B. G. and Armstrong, S. W. 1978. Increases in nuclear volume and cell size in meristematic cells arrested by 5-aminouracil. Protoplasma 96: 47-57.

Goldstein, L. and Ko, C. 1981. Distribution of proteins between nucleus and cytoplasm of Amoeba proteus. J. Cell Biol. 88: 516-525.

Jakob, K. M. and Bovey, F. 1969 . Early nucleic acid and protein synthesis and mitosis in the primary root tips of germinating Vicia faba. Exp. Cell. Res. 54: 118-126.

Jeter, J. R, Jr and Cameron, I. L. 1974. Acidic nuclear proteins and the cell cycle. In: Acidic Proteins of the Nucleus (ed. I. L. Cameron and J. R. Jeter, Jr.) pp. 213-245. SpringerVerlag. New York.

Kubitschek, J. E. 1966. Generation times: ancestral dependence and dependence upon cell size. Exp. Cell Res. 43: 30-38.

Le Stourgeon, W. M. and Rusch, H. P. 1971. Nuclear acidic protein changes during differentiation in Physarum polycephalum. Science 174: 1233-1236. 
-, -, Totten, R. and Forer, A. 1974. The nuclear acidic proteins in cell proliferation and differentiation. In: Acidic Proteins of the Nucleus (ed. I. L. Cameron and Jeter, J. R., Jr.) pp. 159-190. Springer-Verlag. New York.

Levy, R., Levy, S., Rosenberg, S. A. and Simpson, R. T. 1973. Selective chromatin protein synthesis in lymphoid cells by phytohemagglutinin. Biochmestry 12: 224-228.

Liskay, R. M., Leonard, K. E. and Prescott, D. M. 1979. Different Chinese hamster cell lines express a $\mathrm{G}_{1}$ period for different reasons. Somat. Cell Genet. 5: 615-623.

Lyndon, R. F. 1967. The growth of the nucleus in dividing and non-dividing cells of the pea root. Ann. Bot. 31: 133-146.

Matsumoto, Y., Yasuda, H., Mita, S., Marunouchi, T. and Yamada, M. 1980. Evidence for the involvement of $\mathrm{H} 1$ histone phosphorylation in chromosome condensation. Nature 284: 181-183.

Mirsky, A. E. and Ris, H. 1949. Variable and constant components of chromosomes. Nature 163: $666-667$.

Mitchell, J. P. 1967. Combined protein and DNA measurements in plant cells using the dinitrofluorobenzene and Feulgen techniques. J. Roy. Micr. Soc. 87: 375-381.

Murin, A. 1967. Onset of mitosis and first mitotic cycles in germinating seeds of Vicia faba. The Nucleus 10: 190-193.

Patau, K. 1952. Absorption microspectrophotometry of irregular-shaped objects. Chromosoma 5: 341-362.

Prescott, D. M. 1955. Relations between cell growth and cell division. I. Reduced weight, cell volume, protein content and nuclear volume in Amoeba proteus from division to division. Exp. Cell Res. 9: 328-336.

- 1966. The synthesis of total macronuclear protein, histone and DNA during the cell cycle in Euplotes eurystomus. J. Cell Biol. 31 : 1-9.

Socher, S. H. and Davidson, D. 1971. 5-aminouracil treatment: a method for estimating $G_{2}$. J. Cell Biol. 48: 248-252.

Stein, G. S. and Baserga, R. 1970. The synthesis of acidic nuclear proteins in the prereplicative phase of the isoprotenerol-stimulated salivary gland. J. Biol. Chem. 245: 6097-6105.

Thomas, J. E. and Davidson, D. 1981. Effect of ambient water volume on root growth, cell cycle duration and mitotic synchrony during germination and seedling growth of Vicia faba. Can. J. Bot. 59: 1301-1306.

- and - 1982. Cell cycle kinetics in the primary root meristem of Vicia faba: the influence of different ambient water levels. Caryologia 35: 191-203.

— and - 1983. Cell and nuclear size in roots of Vicia faba: changes during germination and in response to different ambient water levels. Ann. Bot. 51: 353-361.

Van't Hof, J. 1975. DNA fiber replication in chromosomes of a higher plant (Pisum sativum). Exp. Cell Res. 93: 95-104.

Zetterberg, A. and Killander, D. 1965. Quantitative cytochemical studies of interphase growth. II. Derivation of synthesis curves from the distribution of DNA, RNA and mass values of individual mouse fibroblasts in vitro. Exp. Cell Res. 39: 22-32. 